\title{
Chapter 2 \\ One Size Does Not Fit All: The Importance of Contextually Sensitive mHealth Strategies for Frontline Female Health Workers
}

\author{
Amina Tariq and Sameera Durrani
}

\begin{abstract}
Health solutions represent an exciting new frontier in the fight against myriad health challenges faced in the developing world, where the use of mobile phones has become pervasive across various socioeconomic boundaries. The principal users of these solutions are frontline healthcare workers; mostly women, often working at the lowest rung of health hierarchy. The distinctive value of this workforce lies in its ability to successfully deliver health services whilst being sensitive to the culture and context of their communities. Since these women are from the client communities, they can speak to them in ways outsiders cannot. Using a contextualized case study of lady health workers (LHWs) working in rural areas of Pakistan, this chapter demonstrates how the potential represented by such frontline health workers can be maximized. To this end, it draws upon in-depth longitudinal qualitative accounts of eight LHWs involved in a 2-year pilot mHealth project to improve antenatal health care. This chapter uncovers how sociocultural barriers - such as prohibitive financial concerns and gender-based discriminationinhibit acceptance of mHealth solutions in Pakistan. The study found that these barriers adversely impact both LHWs' initial adoption of mobile devices as well their inclination to continue using mHealth solutions. This chapter explores how macro- and micro-level communication strategies can be used to ease these barriers. It also explores how LHWs themselves can use mobile technology to better connect with their client communities. If mHealth is to be the brave new frontier in the domain of health innovations, we need to do more to understand the finer points of its contextually sensitive applications. This chapter seeks to explore how this can become a reality for rural areas of Pakistan.
\end{abstract}

\footnotetext{
A. Tariq $(\square)$

School of Public Health and Social Work, Queensland University of Technology,

Queensland, Australia

e-mail: a.tariq@qut.edu.au

S. Durrani

School of the Arts and Media, University of New South Wales, Sydney, Australia

(C) Asian Development Bank 2018

E. Baulch et al. (eds.), mHealth Innovation in Asia, Mobile Communication in Asia:

Local Insights, Global Implications, https://doi.org/10.1007/978-94-024-1251-2_2
} 
Keywords Lady health worker $\cdot$ mHealth Pakistan Context sensitive Communication strategy $\cdot$ Mass media

\subsection{Introduction}

Community health workers (CHWs) in many low- and middle-income countries are a fundamental part of the health service delivery structure (Haines et al., 2007; Maes, Closser, Vorel, \& Tesfaye, 2015; Perry, Zulliger, \& Rogers, 2014). A 2014 review of the role and performance of CHWs ascertains that more than five million frontline workers are active globally (Perry et al., 2014). CHWs can occupy the lowest rung of health hierarchy, work on the frontline, come from the modest social, economic, educational backgrounds, are often women, and are likely to serve their own communities (Bhatia, 2014; Haines et al., 2007; Kane et al., 2016). These frontline CHWs have been instrumental in providing a range of health services ranging from provision of antenatal and postnatal care, safe childbirth, counseling on breastfeeding, immunizations, management of uncomplicated childhood illnesses, general health education and promotion on malaria, tuberculosis, HIV/AIDs, and facilitating access to healthcare services (Kok et al., 2015; Lewis, 2010; Perry et al., 2014; Perry \& Zulliger, 2012). CHWs in many cases are the first point of healthcare contact in their communities and usually have high school education (between year 8 and 10) which is supplemented with up to 3 years para-professional training (Closser, 2015; Kok et al., 2015; Lewis, 2010).

Many recent reviews of the performance of frontline healthcare workers recognize that despite limitations in the quality of available evidence, these workers have an important role in increasing coverage of essential interventions for child survival and other health priorities (Kane et al., 2016; Kok et al., 2015; Lewis, 2010; Perry et al., 2014). One distinguishing characteristic of this frontline workforce is its ability to provide healthcare services while being sensitive to the culture and context of host communities (Bhatia, 2014; Maes et al., 2015; Mbuagbaw et al., 2015; Mumtaz et al., 2013). This characteristic is part of the minimum guidelines for CHW selection set by the World Health Organization: "CHWs should be members of the communities where they work, should be selected by the communities, should be answerable to the communities for their activities, should be supported by the health system but not necessarily a part of its organization, and have shorter training than professional workers" (Lehmann \& Sanders, 2007). As recognized by Maryse et al. in their recent systematic review, retention and performance is better in programs where selected CHWs are trusted members of the community and better reflect the linguistic and cultural diversity of the population served (Kok et al., 2015). This contextually sensitive healthcare service provided by frontline female workers is particularly beneficial for maternal care in conservative communities of the developing world (Hurt, Walker, Campbell, \& Egede, 2016; Mbuagbaw et al., 2015; Mumtaz et al., 2013). Female healthcare workers - as they 
belong to the same community-have a comfort level with their patients, which is not possible to establish for a healthcare professional from outside the community.

Acknowledging the instrumental role of frontline healthcare workforce, various educational and technological interventions are being introduced with the intention to improve the quality of care provided by CHWs (Howitt et al., 2012, p. 508). There is growing interest in the use of mobile information and communication technologies (commonly referred to as mHealth) to revolutionize the work of CHWs in low-resource settings by providing them with efficient communication and data collection systems (Akter \& Ray, 2010; Buehler, Ruggiero, \& Mehta, 2013; Chib, 2013; Hurt et al., 2016; Mechael, 2009; Tomlinson et al., 2009). Partly as a result, there is a wide body of literature across many developing countries that reports on mHealth interventions with CHWs as the primary users of the mHealth technologies (Buehler et al., 2013; Chib, 2010; DeRenzi et al., 2011; Kumar et al., 2015; Ramachandran, Canny, Das, \& Cutrell, 2010). Possible mHealth applications span different types of tasks performed by CHWs including data collection and reporting, information and decision support applications, and communication with healthcare professionals and patients (Chib, 2013; Hall, Fottrell, Wilkinson, \& Byass, 2014).

Despite the plethora of pilot mHealth projects initiated in developing countries over the past decade, there is general agreement amongst researchers that existing evidence is rather too limited to easily permit any "scaling-up" of mHealth initiatives (Aranda-Jan, Mohutsiwa-Dibe, \& Loukanova, 2014; Chib, 2013; Hall et al., 2014; Hurt et al., 2016; Källander et al., 2013; O’Donovan, Bersin, \& O’Donovan, 2015; Tomlinson, Rotheram-Borus, Swartz, \& Tsai, 2013). Appropriate consideration of sociocultural factors in the design of mHealth interventions is identified as one of the prerequisites to enable the much-needed shift from the pilot to a scalable mHealth paradigm. Aranda-Jan et al. suggest in their review of mobile health projects in Africa that even if pilot projects are perceived to be useful by one particular community or set of users, there are still questions regarding the acceptance of mHealth technologies by other communities, as receptiveness is limited by socioeconomic and sociocultural factors (Aranda-Jan et al., 2014, p. 12). This is further confirmed by a recent systematic review of factors effecting mHealth adoption by healthcare professionals conducted by Gagnon et al. which included mHealth adoption studies conducted both in developed and developing countries (Gagnon, Ngangue, Payne-Gagnon, \& Desmartis, 2016). This review observes that along with some common factors (e.g., perceived usefulness of mHealth) across developed and developing countries, studies in developing countries identified five factors that were not mentioned in studies across developed world (Gagnon et al., 2016). These factors included professional security, support and promotion of mHealth by colleagues, additional tasks, material resources as well as communication and collaboration effort (Gagnon et al., 2016). Sociotechnical consideration of mHealth requires going beyond basic evaluation of proving mHealth works to examining the contextual conditions on what and how these solutions do or do not work (Buehler et al., 2013; van Heerden, Tomlinson, \& Swartz, 2012; PLOS Medicine Editors, 2013; Tomlinson et al., 2013). 
mHealth research therefore needs to shift from its techno-deterministic design focus to a contextually informed technology design focus- to ensure that technology is appropriately used in the context of achieving the specific health goals it was intended to meet (Davis, DiClemente, \& Prietula, 2016; Fiordelli, Diviani, \& Schulz, 2013). This shift requires diversification from both theoretical and methodological perspectives especially drawing on rich theoretical perspectives of communication and media literature (Kumar et al., 2013). Arguably, there is currently some disconnection of expertise-health professionals are qualified to say what the content of the messages needs to be while media professionals are better aware of the form these messages must take and the platforms most suitable for dissemination of these messages. We propose in this chapter that both mHealth practice and research provides important opportunities to challenge the theoretical assumptions embedded in current information systems theory, which has often been conceived within an industrial setting. The requirement now is for the development of contextually nuanced theory which is meaningful to the multidisciplinary context of the mHealth domain (Chiasson and Davidson, 2004; Chiasson et al., 2007).

This chapter brings together ideas from both domains and draws on literature that looks at the use of mobile communication as well as providing a historical overview of how mass media campaigns have been employed to support CHW programs in Pakistan. This chapter specifically aims to examine the contextually sensitive mHealth possibilities that exist within Pakistan with reference to better facilitation of communication at the interpersonal, group, and mass audience level. By drawing on a contextualized case study of mHealth implementation, it examines what type of mobile communication technologies are potentially available for frontline lady healthcare workers (LHWs) and how media can be better utilized to facilitate holistic acceptance of the LHW program as well as the technology appended to the program.

\section{2 mHealth Implementation for Antenatal Care in Pakistan}

This section describes a case study of a pilot mHealth project implemented in Pakistan between 2008 and 2010. Our aim is to provide appropriate background and implementation details of the project which will then be used to inform the discussion of proposed contextually sensitive communication strategies in Sect. 2.3.

\subsubsection{Lady Health Workers: Primary Carers for Rural Mothers in Pakistan}

In 1993, the Government of Pakistan launched the National Program for Family Planning and Primary Health Care (NPFP\&PHC). This was done in order to fill the 
gaps created by the ever-increasing population's health needs and the deficient facility-based care mechanisms at the primary level, as well as to reduce unnecessary workload on higher level centers. The program was launched with the slogan of "Promoting health: Reducing poverty by bridging the gap between Health Services and communities, we provide quality Integrated Health Services at the doorstep of our communities" (Wazir, Shaikh, \& Ahmed, 2013). The government program is structured around rural health centers (RHCs) and basic health units which are staffed by doctors, lady health visitors, lady health workers (LHWs), and trained birth assistants (Aqil, 2012; Siddiqui, Shah, \& Memon, 2010). The program has gradually expanded since its inception and has involved more than 100,000 LHWs who provide preventive and basic curative services at the household level throughout the country (Garwood, 2006). While the term "lady" may seem rather old-fashioned to a native English language speaker, it is pertinent to note here the prestige and respect it carries within the Pakistani context of its use. It is the closest translation of the Urdu word khatoon, a title of respect used for an adult woman. Using the English translation as a title for these workers may have been a way of conferring further prestige and credibility onto their roles.

A LHW is eligible for employment if she has the minimal qualification of at least 5 and preferably 8 years of formal schooling. She has to be essentially a resident in the locality where she is to be assigned. This hiring is done at the district level by district health departments. The LHWs are linked with the Basic Health Units (BHU) administratively, and for referral of patients. They report to the BHU on a monthly basis and receive regular refresher training at the same venues (Garwood, 2006). Each LHW is designated to $150-200$ households, or a population of about 1000. There are about 12-20 LHWs in the catchment area of each BHU (Closser \& Jooma, 2013; Garwood, 2006; Mumtaz et al., 2013).

The LHWs focus on promoting healthy behaviors during the maternal period, through health education for risk of complications during pregnancy, safe practices for delivery, nutritional advice, and appropriate breastfeeding practices. A LHW is expected to: assess risk in pregnant woman based on maternal age, weight, height, and past obstetrical history; record anemia and ankle oedema and fundal height against gestational age each month; educate on the importance of tetanus toxoid vaccinations during pregnancy and on fetal movement/kicking. The LHW is also expected to refer women to higher levels of care (i.e., health facilities) if pregnancy-related complications are observed during the routine monthly household visits or are reported by the pregnant woman.

LHWs are supervised by Lady Health Visitors (LHVs) who undergo a 2-year training program that comprises 1 year of midwifery and a second year in paediatrics and tropical diseases (Ariff et al., 2010). She is qualified to conduct deliveries at household and facility level, and provides immediate newborn care. Each LHV usually supervises 20-25 LHWs. A supervisor LHV is responsible for training LHWs, and ensuring quality performance by LHWs by collecting monthly reports from the LHWs which provide information on type of cases encountered and relevant services provided (Rabbani et al., 2014, 2016). 


\subsubsection{Antenatal Care in Pakistan: Proposed mHealth Monitoring Solutions}

To reflect on the lessons learned from the case study, the following subsections provide some necessary project background. The complete proposal of the project is available for open access from the National ICT R\&D website www.ictrdf.org.pk/ (Rao, 2010).

\subsubsection{Project Background}

The project under discussion was titled "Remote Patient Monitoring System with Focus on Antenatal Care for Rural Population", an innovative 14.8 million (PKR) project funded by Pakistan's National ICT R\&D fund in 2008. National ICT R\&D is a government-affiliated organization which aims to "Transform Pakistan's economy into a knowledge based economy by promoting efficient, sustainable and effective ICT initiatives through synergic development of industrial and academic resources" (National Information Communication Technology Research \& Development [ICT R\&D], 2017).

At the time, the project was one of very few mHealth projects initiated in Pakistan. The primary objective of this 28-month pilot project was to develop a reliable, efficient, and easily deployable remote patient monitoring system that can play a vital role in providing basic health services to the remote village population of Pakistan at their doorstep. The aim was to design a generic remote healthcare system with a focus on antenatal care, and use ICT advancements to develop a monitoring system that could enhance the quality of health care provided by the LHWs.

In order to evaluate the performance of the project, the following performance indicators were defined: (i) LHWs' capacity, (ii) number of correct referrals, (iii) reduction in complexities in birth process through timely preventive measures,

(iv) amount of correct information available during emergency cases, and (v) ultimately a reduction in infant and maternal mortality ratios in the controlled population group. The rationale of this approach was to provide a low-cost and reliable solution to the problem of provision of expert health care to patients in remote areas of Pakistan.

\subsubsection{2 mHealth Solution: Overall Proposed Design}

The proposed mHealth solution at the conception stage of the project incorporated the use of a remote patient monitoring system, conceived as a system which allows LHWs to fill in patient's antenatal care-related information using a mobile device. The proposed overall architecture of the system consisted of sensors for automatic measurement of patient's vital signs, a data gathering module (DGM) installed on a 
mobile device which allows auto-collection of vital signs data and data entry by LHWs, a clinical decision support system (CDSS) and an electronic medical record (EMR) management system accessible on any web-enabled remote terminal (e.g., a doctor's laptop). The data entered by a LHW on the device was to be transferred in real time to a doctor's computer in a hospital. The CDSS component aimed to provide timely alerts to the doctors on any data anomalies (e.g., very low Hb levels, etc.). This would allow doctors to send their feedback to the respective LHW, who would then treat the patient. Since Pakistan currently does not possess a centralized EMR solution, this system was perceived to be an enabler for long-term management of electronic data for patients, which can then facilitate longitudinal analysis of patients' health and also drive introduction of evidence-based interventions in the public health domain, which are currently and were absent in Pakistan at the time of the project. Figure 2.1 presents a pictorial view of the overall design of the proposed mHealth solution. It is important to clarify that the first pilot phase of the project, which this chapter revolves around, did not include implementation of sensors, and focused primarily on developing data gathering module for LHWs. In this phase, LHWs were responsible for manually entering the collected data into the module on their devices.

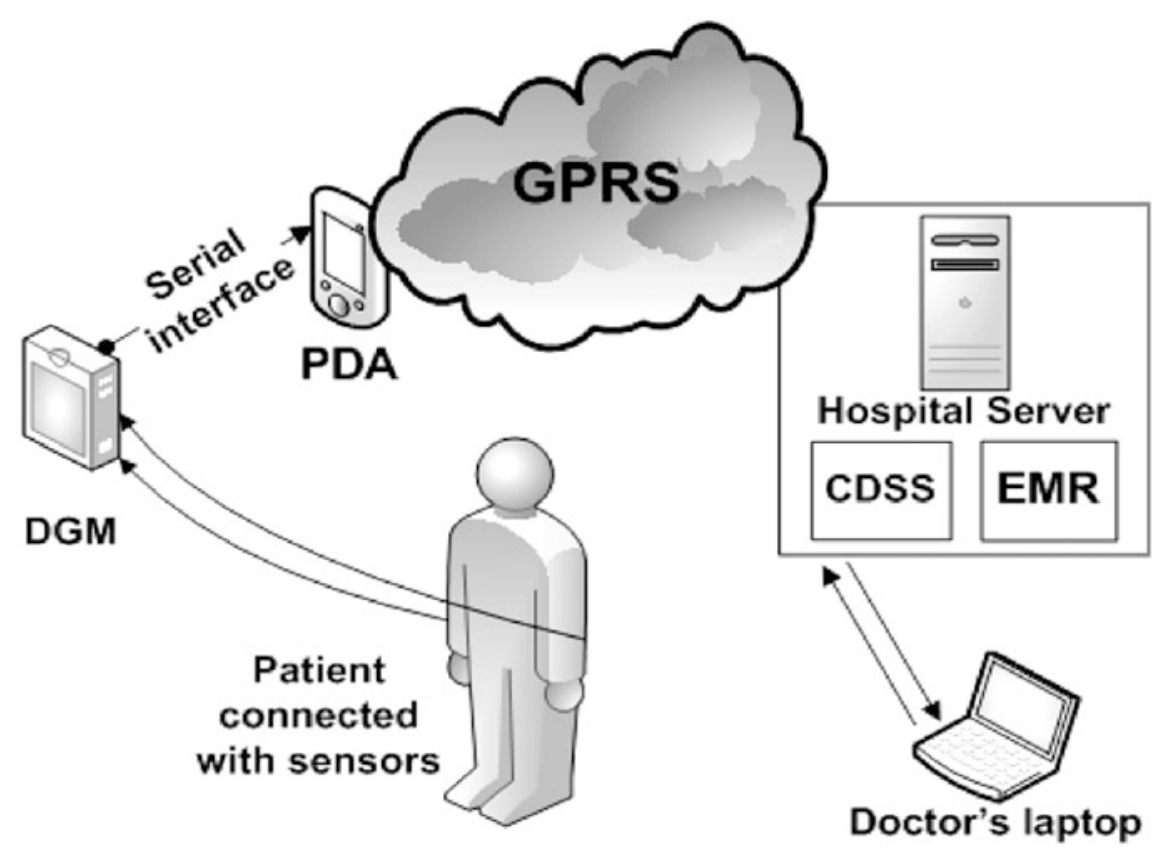

Fig. 2.1 Design of proposed mHealth solution (Khalid, Akbar, Tanwani, Tariq, \& Farooq, 2008) 


\subsubsection{Project Implementation Setting}

In order to better realize the practical and applied context of the project, it was essential to identify a suitable implementation setting for it. For this specific purpose, a controlled population group of pregnant women was identified, along with two expert doctors from a large teaching hospital which serves as the primary hospital to deliver care to the patients. The implementation setting therefore involved collaborative input from two key organizations: the Human Development Fund (HDF) — which coordinated the antenatal care provided by LHWs in the test region-and Rawalpindi General Hospital (RGH), a large teaching hospital responsible for providing care to the patients.

For the scope of this project, the Community Health Centre (CHC) of HDF in Islamabad rural region was targeted as it is the closest to the participating organizations in terms of geographical proximity (Fig. 2.2). This CHC is in control of one unit (comprising of 1000 households) selected from the economically disadvantaged segment of the population from rural areas of Islamabad. It was decided that the services of CHC staff (Doctor, LHV, TBA, and dispenser) would be obtained as part of the project. In order to provide expert advice on antenatal care issues, a consultant gynaecologist from RGH was also involved in the project. She

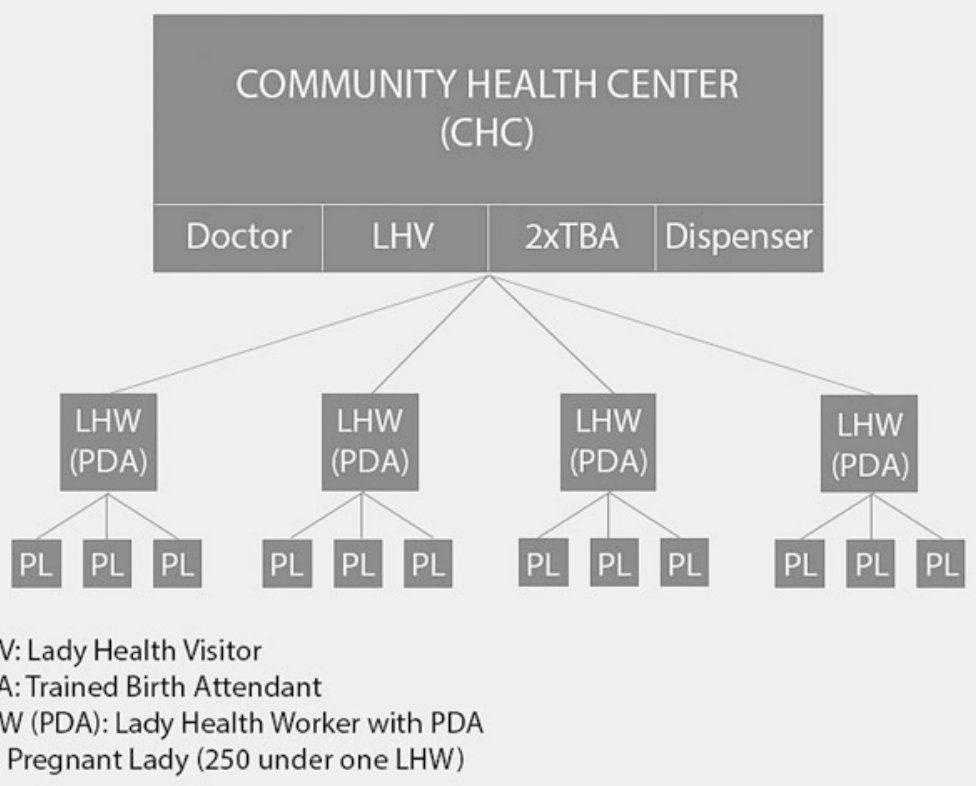

Fig. 2.2 Structure of the participating CHC site (Khalid et al., 2008) 
provided assistance and expert opinion in the development of the overall mHealth solution. The hospital's approval was also obtained to enable transmission of the data to the hospital's main server, which was entered as input by the LHW using her mobile device. It was decided as part of the project plan that the electronic medical records of the patients in the study would be made available to the participating $\mathrm{CHC}$ as well as the National Office of HDF. The communication among RGH, $\mathrm{CHC}$ and National Office of HDF would be carried out through the Internet.

\subsubsection{Project Team}

The project team consisted of the following experts: a principal investigator (Professor of Computer Science), five research engineers with technical expertise in Computer Science, Electrical Engineering and Software Engineering, one medical domain expert (gynaecologist) from RGH and one usability consultant (AT-first author). The team from HDF who participated in the project included a Health Coordinator for the CHC site, a Lady Health Visitor (LHV) and all LHWs serving the $\mathrm{CHC}$ site ( $\mathrm{n}=8$ as 6 full-time, 2 part-time). The trained birth assistant (TBA) and dispenser, as described above, were also invited to participate but had limited engagement with the project.

\subsubsection{Project Implementation Journey}

From the very beginning, it was clear that besides the infrastructure and associated technical challenges (e.g., quality of mobile reception in rural areas), the primary challenge of the project was to engage and train LHWs, the primary users of the mHealth solution. To address this, an initial training plan was devised around a user-centered design framework (Tariq, Tanwani, \& Farooq, 2009), where a series of workshops and site visits were planned to identify LHW requirements, understand their real work context, and train them progressively as the data entry module was developed further. In order to facilitate the understanding of the project outcomes, the project journey from LHWs participation perspective can be divided into three phases: (1) requirement gathering phase, (2) initial testing and user training phase, and (3) postlaunch user feedback.

\subsubsection{Phase 1: Requirements Gathering}

The first phase comprised the first 8 months from project commencement and focused on user requirements gathering to inform system design. Requirements gathering was conducted for different parts of the project, in parallel (Fig. 2.1). This section focuses on requirement gathering for the data gathering module whose primary users were LHWs. Four user workshops were conducted: two at the 
participating community health center and two at the university hosting the project implementation team - to which doctors were also invited.

Contextual interviews and field observation were used to gather data to understand the context in which LHWs are situated. The age distribution of the eight LHWs was quite broad-from 17 to 58 years and their work experience ranged from 5 months to 4 years. Initial interviews revealed that seven of the eight LHWs routinely used mobile phones for interacting with their family and friends via voice calls or SMS. The LHWs' mobiles were not smartphones and did not have a camera, browser, or other more advanced functions. LHWs described very limited use of mobile phones to interact with their patients, mostly confined to informing the patient if they were late for a visit. This limited use was compounded by whether the patient had access to a mobile device and was willing to be contacted by the LHW.

A detailed task analysis identified that the main job of LHWs is to conduct periodic checkups of patients and maintain medical records. These records are documented on standard visit forms collated in a notebook primarily in English language, with occasional translation of data field headings into Urdu. The checkups are classified as "booking visit" or "routine visit". During a booking visit, the LHW logs the basic medical history of women in a new household. This history is structured as personal information, past medical history, family history, social history, previous pregnancies, gynaecological history, and general examination. During a routine visit, LHWs physically examine antenatal patients to determine the weeks of gestation, fundal height, presentation, edema, and anemia. Physiological data are measured - blood pressure, temperature, and pulse. These patient data are recorded in the paper-based register and reported back to a doctor in the nearest health center. Each LHW visits approximately 14 different households every day, meaning that a particular household is visited once a month. The average time spent by a LHW with a patient is about $5-8 \mathrm{~min}$.

Each LHW carries a $5 \mathrm{~kg}$ bag containing notebooks and basic medical instruments. Observations and interviews revealed that LHWs were willing to adapt to a new mHealth system if they were convinced that it would improve the efficiency of their visiting schedule.

The outcome of the task analysis identified that a critical factor in selecting a device is the user-friendliness of data entry. The LHWs in this study are comparative novice mobile users and most of them used only voice and SMS features. Hence, the use of the numeric keypad for data entry was unfamiliar to them. This was further aggravated by the need to input 25-30 patient records daily. Therefore, a stylus-based touchscreen device (i-mate JAMA) was selected for the data entry module of the mHealth application (Fig. 2.3). Nine devices were purchased as part of the project, one for each participating LHW and one for project testing. At the time of project implementation the cost of each device was 12,000 PKR (approx. 110 USD). 
Fig. 2.3 Custom data entry module for the i-mate JAMA

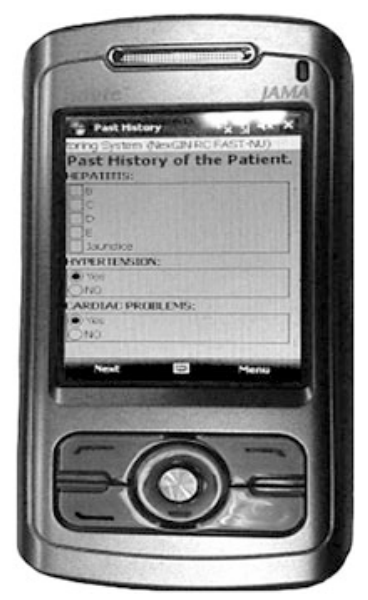

\subsubsection{Phase 2: Initial Testing and User Training}

Following requirements gathering, the project team initiated the development of the data gathering module. The design of the legacy paper-based forms (in English) was adjusted for the mobile interface (Fig. 2.3). Five user workshops were conducted every 2 weeks with the LHWs. During the first two training workshops, the LHWs mostly expressed satisfaction with the design of the form. All agreed that plenty of data entry practice would be required before field trials. The CHC coordinator and the LHV identified proposed that the LHWs enter at least 10-15 records daily for 2 months in order to gain confidence with the data entry module. This introductory training period would also allow the implementation team to iteratively test the mHealth application design.

For the third and fourth training workshops, the implementation team walked the LHWs through the data entry process a few times and helped the LHWs to enter data live while attending some patients (Fig. 2.4). The application required Internet access for data upload and the weak connection at the CHC site and throughout the rural region delayed real-time synchronization. LHWs clarified that only one of them had Internet access at home and would either need to rely on $3 \mathrm{G}$ service availability or visit a $\mathrm{CHC}$ site to upload data. The slow upload and inability to recognize if data had been successfully uploaded increased anxiety among LHWs. Based on this feedback, it was recognized that both offline storage capacity and data upload confirmation messages should be added to the system.

Three LHWs reported that mobile data entry was much slower than the paper-based entry to which they were accustomed. During the fourth training workshop, the oldest LHW refused to enter more than three fields on the data entry module as she found it very stressful and asked to be excused from the project. She 


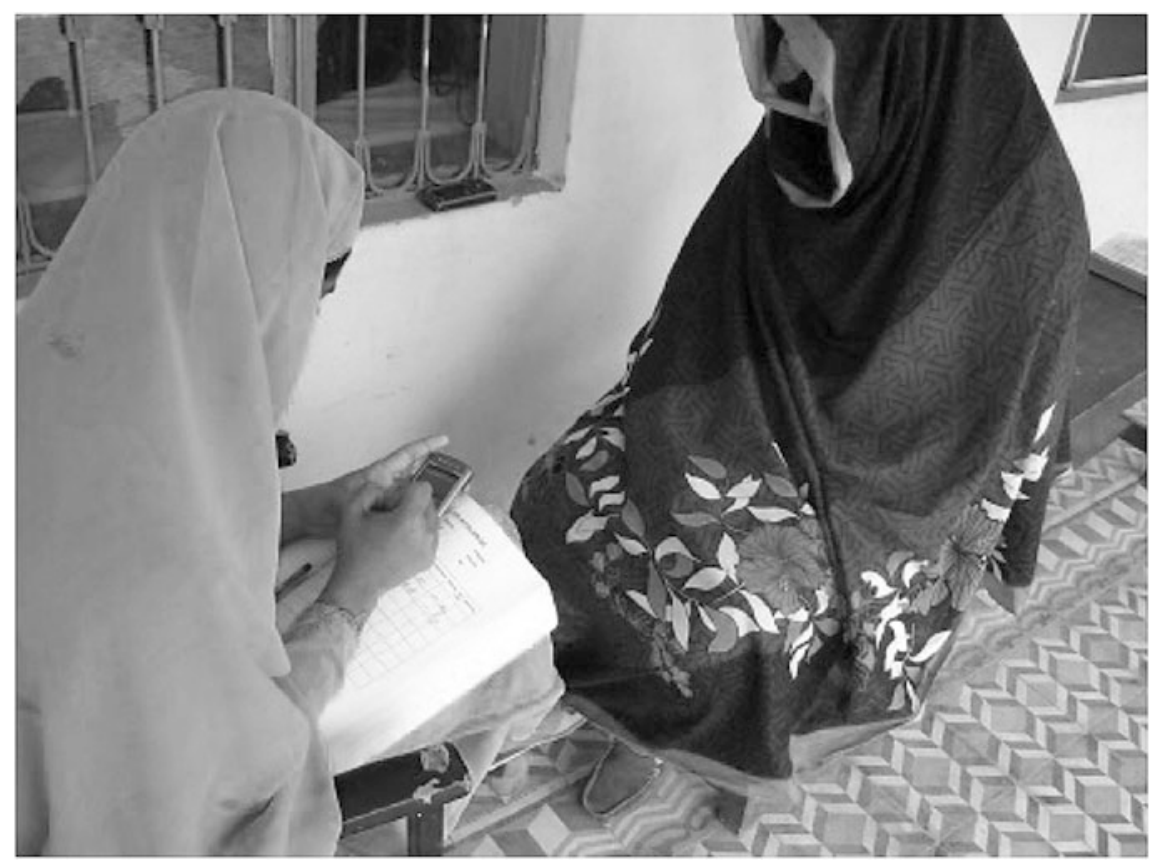

Fig. 2.4 LHW collecting patient data via mobile (Tariq et al., 2009)

was encouraged to persevere and seek help from her LHW colleagues as required. After the fourth training workshop, the devices were left with at the CHC site for LHWs to practice data entry.

At the commencement of the next workshop, it was announced that the oldest LHW was very uncomfortable with the mHealth project and had left to join a different site for work. Another LHW indicated that she intended to find another site to work at as her father did not approves of her carrying a personalized smartphone with a camera and Internet access. Four of the younger LHWs ( $<28$ years) expressed that they really liked using the mobile application for data entry but they had been working overtime - almost four hours each day for the previous 2 weeks - to practice data entry without any financial compensation. All LHWs were concerned about being responsible for an expensive device worth almost twice their monthly salary. Those LHWs married with young children - or attending patients with young children-were worried that children's playful activities might damage the device. Others were concerned that members of their family with a substance addiction might steal and sell the device to obtain money for drugs. In response, the project investigators identified the need for an overtime budget for the LHWs; in terms of device security it was suggested that the mobiles be collected and returned from the CHC daily. 


\subsubsection{Phase 3: Postlaunch User Feedback}

The final phase lasted about 7 months and centered upon full implementation including real-time data entry by LHWs, data review by hospital-based doctors, and the sharing of feedback between doctors, the LHV and LHWs. A technical support line was established for LHWs in case of any issues with the mHealth application. Most of the patient data collected via the mHealth application was received between 2:30-5:30 pm from which it was inferred that the LHWs were not using the mHealth application for data input at the patient's home as instructed, but were retrospectively entering data from paper-based records toward end of the day.

The consultant made three visits to the CHC site to gain feedback from LHWs and the LHV and to observe their use of the mHealth application. During these visits the LHV identified that she retained one of the devices (left by the LHW who left the group) for herself in case she needed to provide further training. Further feedback from the LHV indicated that some of patients and their husbands were not comfortable with LHWs using mobile devices while attending them during their visits. Therefore, most LHWs preferred taking their paper registers with them and entering the data electronically after completing their daily visits. Further discussions with LHWs revealed that - despite promises from their supervisors - they had not been financially compensated for overtime incurred on the project. One of the LHWs stated that she would leave the site soon as she found it impossible to cope with her increased workload without any extra compensation while being the sole provider for her family. The LHWs shared the reluctance of some patients' husbands to let LHWs use the devices while attending their wives as they believed it to be an inappropriate collection of private information. LHWs concerns about device theft were reiterated and there was agreement that limited effort had been made by the whole project team to create community awareness of the introduction of mobile devices to improve patient care as well as reduce concerns about data security.

\subsection{The Way Forward}

Both mHealth research and practice can address so-called wicked sociotechnical problem with no mechanistically deterministic resolution (Westbrook et al., 2007). mHealth projects may be characterized by abrupt stop-and-start approaches whereby a set of new measures is tested with insufficient consideration of how to normalize these interventions as part of the social fabric at the test site. This section looks at how communication practices can help to better enable sustainability with reference to mHealth. Two practices are discussed: mobile communication as a tool for enhancing the performance of LHWs, and mass communication as a facilitator for ensuring that LHWs work in a favorable environment. 


\subsubsection{Incorporating Communication into mHealth Programs}

The case study above offers useful insights for the design a more proactive communication strategy which accounts for the evolution of communication technology in the country of implementation. The LHWs in this study did not possess smartphones - in Pakistan at this time, Nokia handsets dominated the market, smartphones were a novelty and gender was a significant factor on device accessibility within the family unit. Ownership rates have since accelerated: 53\% of the adult Pakistani population now owns a cell phone, up from 5\% in 2002 (Dawn News, 2015). Companies such as QMobile manufacture smartphones for the Pakistani market starting from USD 58 and estimates put the number of smartphone users at about 40 million (Baloch, 2015). There is also a generational shift: younger women - and therefore younger mothers - are more likely to have a mobile device (Qamar, 2009).

\subsubsection{Contextually Sensitive Technological Choices}

The rural/urban divide and socioeconomic disparity in this diverse customer base means that different mHealth clients in different areas will have access to different mobile devices. We argue that the concept of audience fragmentation-more usually applied to mass media forums like television (Kosterich \& Napoli, 2015) also applies to mHealth clients. In other words, mHealth project design and implementation will vary according to the demographics of the specific audience "fragment" at each different geographic site. For example, project designers may prefer LHWS to use the same mobile devices that are already prevalent at the site: if the target user has access to a phone that provides text messaging only, then it might make sense for the LHW to communicate with the same device. Additionally, the use of relatively inexpensive and commonly available devices mitigates the risk of theft, with which the LHWs in the study were very concerned.

Within the context of device use, it is important to emphasize adoption of the principle of progressive iterative familiarization in mHealth implementation. The study noted that some LHWs struggled with some aspects of the devices provided such as the touchscreen data entry keypads. An older LHW dropped out of the project altogether, while some took to using the data entry modules in a way that ran counter to project design. New technology can disrupt established social routines and so to ensure more harmonious diffusion, it is suggested that a future project take such information overloads into account. First, the technological devices being employed should be progressively rolled out so that problems encountered by users can be documented and resolved by the implementation team. Second, if the devices are similar to the type of phones that the LHWs already possess, higher adoption rates may be more achievable. 


\subsubsection{Micro-level mHealth Promotion: Benefitting from Existing Technological Options}

Technology circumscribes communication, and it is therefore useful to know what kind of technology is available to client communities. The project team did not incorporate a communication plan into their project, which impacted the project's efficiency and sustainability. This section argues that communication planning undertaken with the help of professional communication advice should be made a part of mHealth project design, and proposes some ideas in this regard.

The case study looks at a rural community using non-smartphone mobile devices. This was, however, a decade ago. If a national or regional level mHealth project was to be implemented in Pakistan today, the project team would need to have data about the kind of devices that are available to specific client communities given the growing diversity in types of available mobile devices. These devices may be smartphones or older phones with limited smart features. The communication plan design will be determined by data about which technological options are available to a client community. To this end, multiple potential sources of data can be accessed by the team. Telcos and local phone retailers can provide data on devices and network usage. Social network companies may be requested to provide data on which networks are used. The team can also contact relevant officials within the health ministry, who may be able to suggest what kinds of content and media have been successfully used in which regions. This research will enable the team to design a more effective communication strategy. A communication campaign for a target LHW patch where the client community uses phones with limited features would have to rely on text messages. If they use smartphones, it may be possible to use social networking services as a messaging platform for health-related behavior change. The team could consult a local communication expert before implementing the communication plan, provided the project funding allows it.

Within a smart/mobile phone context, affordances for community-based communication contribute to two kinds of social capital, which refers to "the connections and the associated norms of reciprocity among people" (Putnam, 2001). There are two categories of social capital: bonding and bridging. Bonding social capital refers to strong-tie relationships such as family or close friends, where people share strong personal or intimate connections and provide emotional support to each other. Bridging social capital refers to weak-tie relationships such as previous co-workers or former classmates, where people do not share a similar background or emotional reciprocity (Piwek \& Joinson, 2016, p. 359).

Social bonding refers to the way mobile apps can be used to build close personal bonds with family and community (e.g., Snapchat). Social bridging refers to loose networking with broader groups (a phenomenon seen within Facebook groups). Depending on the affordances of devices, health communication workers can design messages which work across the spectrum of bonding and bridging. It is possible to create group messages and updates (either text or visual message based) on a specific health issue such as advice about specific nutritional issues during a particular stage of pregnancy. These updates can be delivered to mothers, and serve as 
a reminder/diary. The content of these updates would be dictated by the health experts within the team and their form would be determined by the communication experts. These "diary" references can be referred to and reinforced by the LHWs during patient visits. It is a paperless and cost-effective way of delivering relevant information in a way that can be accessed by the health worker as well as the patient. While this solution will be time-intensive in design, it may assist with longer term efficiency.

It should be acknowledged that apps which facilitate social bridging will be available only to certain client communities depending on smartphone and network availability, as well as the user's level of digital literacy. This is why we suggest that a project team consults a communication expert to assist with the development of a contextually sensitive communication plan.

\subsubsection{Incorporating Immaterial Labor Costs in Project Budgets}

Although our primary focus in this chapter remains on identifying the optimal integration of communication into mHealth programs, it is vital to acknowledge that multiple actors within the mHealth system (e.g., LHWs, regional coordinators, doctors, nurses) will have to learn new skills. One prospective area of concern is the issue raised concerning unpaid overtime for the human resources involved in these projects. For instance, the LHWs included in the study noted that using data input systems cost them more time, which was unpaid. Further incorporation of mobile devices may raise similar issues, since mobile phones make it easy to work from home. A working woman, such as a LHW, is still likely to be perceived as primarily responsible for household tasks. If her work responsibilities are seen as interfering in that domain, she may face more pressure from her family in terms of performing her duties. If she is a given as a mobile device, it may contain a separate contact SIM for work only, and the LHWs can be given the option of keeping these devices on only between 9 and 5 if they wish to avoid overtime. Alternatively, the project budget should contain provisions within it to pay for overtime. We would also like to acknowledge that mHealth project owners may resist incorporating overtime costs into budgets. The research and development organizations funding these pilot projects therefore need to ensure project budgets are designed in a way that ensures that the research participants in mHealth projects are not disadvantaged financially.

\subsubsection{Macro-level Strategies for Increased Acceptance of LHWs}

The previous section looks at how mobile communication can help LHWs connect more effectively with their clients. This is a micro-level communication issue. However, there is a pressing need to create narratives that can help LHWs connect 
better with the larger society. This is a holistic, macro-level issue. The most important resource within the LHW programs are the workers themselves - technology can help improve their performance, but if their ability to work is hampered by broader social and economic frameworks, the impact of their work is diminished significantly in holistic terms. This relates again to the notion of sustainability. If the projects are to have lasting effect, the role of LHWs needs to be given more prestige within society. If the technological devices that are given to them are to have a measurable, consistent impact, their use needs to be normalized not just for the LHWs, but for their clients. The clients need to understand that the unfamiliar devices are implements intended to help them better. This kind of normalization requires the use of mass media platforms.

Human beings often make sense of their world with the help of narratives (O’Shaughnessy \& Stadler, 2005). Narratives, or stories, always assign certain roles more prestige than others. The roles that are more prioritized get more attention, and are perceived as being more significant. It makes sense, therefore, for a communication or marketing campaign designer to structure narratives in a way that prioritises the roles being promoted. This is something that the LHW campaign designers did keep in mind. For culturally sensitive health issues such as birth control, it was important to first create a broader narrative of acceptance within society. As mentioned earlier, the term "Lady Health Worker" itself is an attempt to create a label or brand that evokes prestige and respectability.

The original branding efforts for the program were confined to the mass media, delivered via advertising, and television dramas. When launched in the 1990s, the LHW program relied upon extensive TV commercials, which showed LHWs visiting clients. This was an attempt to normalize a new concept: that a female worker could come to one's home, a private domain, and talk about health issues. The brand image of a stereotypical LHW was a woman in her 30s, young enough to seem modern, in traditional Pakistani garb (shalwar kameez, a long tunic with loose trousers) with a dupatta (loose shawl) covering her head. The discourse, it is noted, has been normalized enough that these ads are no longer seen as needing the same kind of airtime. Conversely, this normalization has had an unintended side effect, as LHWs have now been marginalized into the outer peripheries of media discourse and their challenges relegated to the lower tiers of media agendas.

This relegation in importance has manifested itself in economic marginalization. A string of print news reports from 2012-2016 reported on LHWs protesting about the nonpayment of salaries (as these are nonauthorial reports, see references for a list). In a 2010 episode of the talk show "News Night with Talat", prominent talk show host Talat Hussein hosted a program on the suicide of a LHW stemming from issues of nonpayment (https://www.youtube.com/watch? $=$ LjN3LO7D1ws uploaded 24 Nov 2010). This is an issue that highlights the importance of managing human resources, the key factor upon which this program is structured. If a LHW is impeded by finances and society from fulfilling her work, then the fundamentals on which this project rests are at risk.

This is, once again, where a communication professional may be to provide input at both the macro- and micro-level. As discussed, at the micro-level and in the 
short run, they can help the team to design contextually sensitive communication strategies for specific client communities. At the macro-level, they can help to support a favorable societal attitude toward mHealth and its goals. These options could relate to both traditional and social media. Access to mass audiences is restricted to some extent by considerations of finance. Access to social media, which is rapidly expanding in Pakistan, is much less restricted. For example, UNICEF Pakistan has previously uploaded LHW promotional video to YouTube to (https://www.youtube.com/watch?v=eeJTH1GM7Q0 uploaded 21 Nov 2010).

The organizations working with LHWs also need to develop better connections within Pakistani media in order to generate more news stories-like the UNICEF example above-within mainstream Pakistani channels. The change in discourse has to come from within Pakistan, from Pakistani voices. It is possible to use a two-stage process whereby blog stories written by project affiliates are picked up by influential media outlets such as Dawn and Express. One such example is the Girls can Code series, a collaboration between the technology forum TechJuice and Dawn, one of Pakistan's premier English language newspapers. A series of profile features about pioneering women working within the IT industry was penned by TechJuice writers and published on the Dawn website (see Rizwan, 2016a, b, c, d; Dodhy, 2016a, b). The series received positive feedback from readers and provides one template for a collaboration between a media outlet and a forum that seeks to promote female empowerment.

The case study discussed above represents an example of female empowerment within the urban context. We cite it as an example in which a human-interest angle is used to generate awareness about issues surrounding female empowerment, as well as an instance of the media partnering up with another organization to produce stories. An angle that humanizes LHWs may be one approach suitable for stories placed in the mainstream media. It should also be noted that rural health issues do make it into mainstream news. For instance, stories about infant deaths in the drought-impacted rural region of Tharparkar have dominated headlines in recent years, with coverage from regional news channels eventually making its way into mainstream Pakistani channels (Baloch, 2016). A communication strategy is required whereby awareness can be raised at regional or national levels with a contextually sensitive approach for that level, as devised by communication experts. It is also worth noting here that aside from news, TV drama series popular with Pakistani audiences represent another avenue to raise awareness about women's empowerment and their control over their reproductive rights (Haider, 2017).

The key point here, again, is that there needs to be a communication element to mHealth programs, designed and implemented by people with relevant communication expertise. As the outcomes of the project illustrate, communication needs to be improved on several fronts: between LHWs and project designers, between LHWs and their clients, and between the LHWs and society as a whole. Optimizing communication on these fronts is likely to maximize project outputs on a micro as well as a holistic level. In the long run, these practices will contribute to sustainable practices, the benefits of which will carry over successive projects. Overall our 
findings emphasize the need to embed communication elements within the emerging suite of sociotechnical and user-centered methodological tools (Hughes, Clegg, Bolton \& Machon, 2017), which can be used as a point of reference by practitioners to help implement complex mHealth solutions.

\subsection{Conclusion}

This chapter brings together debates from two contiguous domains: mHealth and communication. Health care is a domain that is intrinsically dependent on communication: the ability of patients to communicate their issues, the ability of health professionals to communicate relevant solutions, and the capacity of the overarching system to effectively mediate the transmission of this information. This need to drive communication is true of mHealth as well-perhaps even more so, given that it is becoming an increasingly community-based domain. This community aspect is what makes it important to examine communication strategies from a contextual perspective. Evidence confirms that mHealth projects have difficulty continuing beyond the pilot phase and the case study discussed in this chapter has argued that contextual factors have a strong impact on project success.

mHealth projects are embedded within broader social structures, cultural and political frames that mediate how power flows within a society, hence project designs that ignore these contextual factors may be doomed. Health professionals may believe that addressing these factors is time-consuming and costly yet the eventual failure of a project is an even bigger waste of resource. This chapter seeks to initiate a debate about possible solutions to such contextual issues through the lever of communication to both identify and solve problems that imperil the sustainability of mHealth projects. It is hoped that the solutions suggested here-while far from perfect - will generate a much-needed discussion on the future design of contextually sensitive mHealth projects.

\section{References}

Akter, S., \& Ray, P. (2010). mHealth-an ultimate platform to serve the unserved. Yearb Med Inform, 2010, 94-100.

Aranda-Jan, C. B., Mohutsiwa-Dibe, N., \& Loukanova, S. (2014). Systematic review on what works, what does not work and why of implementation of mobile health (mHealth) projects in Africa. BMC Public Health, 14(1), 1.

Ariff, S., Soofi, S. B., Sadiq, K., Feroze, A. B., Khan, S., Jafarey, S. N., et al. (2010). Evaluation of health workforce competence in maternal and neonatal issues in public health sector of Pakistan: An assessment of their training needs. BMC Health Services Research, 10(1), 1.

Aqil, A. (2012). Bridging the gap between lady health workers and traditional birth attendants for reducing maternal mortality in rural Pakistan. USA: Brandeis University. Retrieved from http:// works.bepress.com/anushka_aqil/1/. 
Baloch, F. (2015). Telecom sector: Pakistan to have 40 million smartphones by end of 2016. Express Tribune. Retrieved from https://tribune.com.pk/story/953333/telecom-sector-pakistanto-have-40-million-smartphones-by-end-of-2016/.

Baloch, S. (2016). Footprints: Death haunts Tharparkar, again. Dawn. Retrieved from http://www. dawn.com/news/1233906.

Bhatia, K. (2014). Community health worker programs in India: A rights-based review. Perspectives in Public Health, 134(5), 276-282.

Buehler, B., Ruggiero, R., \& Mehta, K. (2013). Empowering community health workers with technology solutions. IEEE Technology and Society Magazine, 32(1), 44-52.

Chiasson, M. W., \& Davidson, E. (2004). Pushing the contextual envelope: Developing and diffusing IS theory for health information systems research. Information and Organization, 14 (3), 155-188.

Chiasson, M., Reddy, M., Kaplan, B., \& Davidson, E. (2007). Expanding multi-disciplinary approaches to healthcare information technologies: What does information systems offer medical informatics? International Journal of Medical Informatics, 76, S89-S97.

Chib, A. (2010). The Aceh Besar midwives with mobile phones project: Design and evaluation perspectives using the information and communication technologies for healthcare development model. Journal of Computer-Mediated Communication, 15(3), 500-525.

Chib, A. (2013). The promise and peril of mHealth in developing countries. Mobile Media \& Communication, 1(1), 69-75.

Closser, S. (2015). Pakistan's lady health worker labor movement and the moral economy of heroism. Annals of Anthropological Practice, 39(1), 16-28.

Closser, S., \& Jooma, R. (2013). Why we must provide better support for Pakistan's female frontline health workers. PLoS Med, 10(10), e1001528.

Davis, T. L., DiClemente, R., \& Prietula, M. (2016). Taking mHealth forward: Examining the core characteristics. JMIR mHealth and uHealth, 4(3), e97.

Dawn News. (2010a). The rise of mobile and social media use in Pakistan. Dawn. Retrieved from http://www.dawn.com/news/1142701.

Dawn News. (2010b). News Night with Talat-Lady Health worker commit suicide-Part-1. Retrieved from https://www.youtube.com/watch?v=LjN3LO7D1ws.

DeRenzi, B., Borriello, G., Jackson, J., Kumar, V. S., Parikh, T. S., Virk, P., \& Lesh, N. (2011). Mobile phone tools for field-based health care workers in low-income countries. Mount Sinai Journal of Medicine, 78(3), 406-418. doi:https://doi.org/10.1002/msj.20256. Retrieved from https://www.ncbi.nlm.nih.gov/pubmed/21598267.

Dodhy, M. (2016a). Meet Noor Fatima, game developer at 'WeRPlay'. Dawn. Retrieved from http://www.dawn.com/news/1292593.

Dodhy, M. (2016b). Meet Sana Khan, head of digital transformation at Telenor Pakistan. Dawn. Retrieved from http://www.dawn.com/news/1293834.

Fiordelli, M., Diviani, N., \& Schulz, P. J. (2013). Mapping mHealth research: A decade of evolution. Journal of Medical Internet Research, 15(5), e95.

Gagnon, M. P., Ngangue, P., Payne-Gagnon, J., \& Desmartis, M. (2016). m-health adoption by healthcare professionals: A systematic review. Journal of the American Medical Informatics Association: JAMIA, 23(1), 212-220.

Garwood, P. (2006). Pakistan, Afghanistan look to women to improve health care. Bulletin of the World Health Organization, 84(11), 845-847.

Haider, S. (2017). Mawra Hocane's Sammi is a slow unravelling of one of Pakistan's darkest truths. Dawn. Retrieved from http://images.dawn.com/news/1177053/mawra-hocanes-sammiis-a-slow-unravelling-of-one-of-pakistans-darkest-truths.

Haines, A., Sanders, D., Lehmann, U., Rowe, A. K., Lawn, J. E., Jan, S. ... Bhutta, Z. (2007). Achieving child survival goals: Potential contribution of community health workers. The Lancet, 369(9579), 2121-2131.

Hall, C. S., Fottrell, E., Wilkinson, S., \& Byass, P. (2014). Assessing the impact of mHealth interventions in low-and middle-income countries-What has been shown to work? Global Health Action, 7. 
Howitt, P., Darzi, A., Yang, G. Z., Ashrafian, H., Atun, R., Barlow, J. ... Wilson, E. (2012). Technologies for global health. Lancet (London, England), 380(9840), 507-535. doi:https:// doi.org/10.1016/S0140-6736(12)61127-1.

Hughes, H. P., Clegg, C. W., Bolton, L. E., \& Machon, L. C. (2017). Systems scenarios: A tool for facilitating the socio-technical design of work systems. Ergonomics, 1-17.

Hurt, K., Walker, R. J., Campbell, J. A., \& Egede, L. E. (2016). mHealth interventions in low and middle-income countries: A systematic review. Global Journal of Health Science, 8(9), 183.

Källander, K., Tibenderana, J. K., Akpogheneta, O. J., Strachan, D. L., Hill, Z., ten Asbroek, A. H. ... Meek, S. R. (2013). Mobile health (mHealth) approaches and lessons for increased performance and retention of community health workers in low-and middle-income countries: A review. Journal of Medical Internet Research, 15(1), e17. doi:https://doi.org/10.2196/jmir.2130.

Kane, S., Kok, M., Ormel, H., Otiso, L., Sidat, M., Namakhoma, I. ... de Koning, K. (2016). Limits and opportunities to community health worker empowerment: A multi-country comparative study. Social Science \& Medicine, 164, 27-34.

Khalid, M. Z., Akbar, A., Tanwani, A. K., Tariq, A., \& Farooq, M. (2008). Using telemedicine as an enabler for antenatal care in Pakistan. 2nd International Conference E-Medisys: E-Medical Systems, Sfax.

Kok, M. C., Dieleman, M., Taegtmeyer, M., Broerse, J. E., Kane, S. S., Ormel, H. ... de Koning, K. A. (2015). Which intervention design factors influence performance of community health workers in low- and middle-income countries? A systematic review. Health Policy and Planning, 30(9), 1207-1227. Retrieved from https://www.ncbi.nlm.nih.gov/pmc/articles/ PMC4597042/.

Kosterich, A. A., \& Napoli, M. (2015). Reconfiguring the audience commodity: The institutionalization of social TV analytics as market Information regime. Television \& New Media, 17(3), 254-271.

Kumar, N., Perrier, T., Desmond, M., Israel-Ballard, K., Kumar, V., Mahapatra, S. ... Anderson, R. (2015). Projecting health: Community-led video education for maternal health. In Proceedings of the Seventh International Conference on Information and Communication Technologies and Development (vol. 15; pp. 17). Association for Computing Machinery. doi: https://doi.org/10.1145/2737856.2738023.

Kumar, S., Nilsen, W. J., Abernethy, A., Atienza, A., Patrick, K., Pavel, M. ... Swendeman, D. (2013). Mobile health technology evaluation: The mHealth evidence workshop. American Journal of Preventive Medicine, 45(2), 228-236. Retrieved from https://www.ncbi.nlm.nih. gov/pmc/articles/PMC3803146/.

Lehmann, U., \& Sanders, D. (2007). Community health workers: What do we know about them. The State of the Evidence on Programmes, Activities, Costs and Impact on Health Outcomes of using Community Health Workers (1-42). Geneva: World Health Organization.

Lewis, J. (2010). Busia child survival project (Final Evaluation Report). African Medical and Research Foundation (AMREF), United States Agency for International Development (USAID).

Maes, K., Closser, S., Vorel, E., \& Tesfaye, Y. (2015). Using community health workers. Annals of Anthropological Practice, 39(1), 42-57.

Mbuagbaw, L., Medley, N., Darzi, A. J., Richardson, M., Habiba Garga, K., \& Ongolo-Zogo, P. (2015). Health system and community level interventions for improving antenatal care coverage and health outcomes. Cochrane Database of Systematic Reviews, 12. doi:https://doi. org/10.1002/14651858. Retrieved from http://onlinelibrary.wiley.com/. doi/https://doi.org/10. 1002/14651858.CD010994.pub2/abstract.

Mechael, P. N. (2009). The case for mHealth in developing countries. Innovations: Technology, Governance, Globalization, 4(1), 103-118.

Mumtaz, Z., Salway, S., Nykiforuk, C., Bhatti, A., Ataullahjan, A., \& Ayyalasomayajula, B. (2013). The role of social geography on lady health workers' mobility and effectiveness in Pakistan. Social Science and Medicine, 91, 48-57. 
National Information \& Communication Technologies: Research \& Development. (2017). Ministry of Technology, Government of Pakistan. Retrieved from http://www.ictrdf.org.pk/ beta/index.php/about-us/our-vision.

O'Donovan, J., Bersin, A., \& O'Donovan, C. (2015). The effectiveness of mobile health (mHealth) technologies to train healthcare professionals in developing countries: A review of the literature. BMJ Innovations, 1(1), 33-36.

O'Shaughnessy, M., \& Stadler, J. (2005). Media and Society: An Introduction (3rd ed.). Melbourne: Oxford University Press.

Perry, H., \& Zulliger, R. (2012). How effective are community health workers. An overview of current evidence with recommendations for strengthening community health worker programs to accelerate progress in achieving the health-related Millennium Development Goals. Baltimore: Johns Hopkins Bloomberg School of Public Health.

Perry, H. B., Zulliger, R., \& Rogers, M. M. (2014). Community health workers in low-, middle-, and high-income countries: An overview of their history, recent evolution, and current effectiveness. Annual Review of Public Health, 35, 399-421.

Piwek, L., \& Joinson, A. (2016). "What do they snapchat about?" Patterns of use in time-limited instant messaging service. Computers in Human Behavior, 54, 358-367.

PLOS Medicine Editors. (2013). A reality checkpoint for mobile health: Three challenges to overcome. PLoS Med, 10(2), e1001395.

Putnam, R. D. (2001). Social capital: Measurement and consequences. Canadian Journal of Policy Research, 2, 41-51.

Qamar, S. (2009). Mobile phone technology growing fast in Pakistan: WB. The Nation. Retrieved from http://www.nation.com.pk/Business/27-May-2009/Mobile-phone-techonology-fastgrowing-in-Pakistan-WB.

Rabbani, F., Mukhi, A. A. A., Perveen, S., Gul, X., Iqbal, S. P., Qazi, S. A. ... Aftab, W. (2014). Improving community case management of diarrhoea and pneumonia in district Badin, Pakistan through a cluster randomised study - The NIGRAAN trial protocol. Implementation Science, 9(1), 1. https://doi.org/10.1186/s13012-014-0186-9.

Rabbani, F., Shipton, L., Aftab, W., Sangrasi, K., Perveen, S., \& Zahidie, A. (2016). Inspiring health worker motivation with supportive supervision: A survey of lady health supervisor motivating factors in rural Pakistan. BMC Health Services Research, 16(1), 397.

Ramachandran, D., Canny, J., Das, P. D., \& Cutrell, E. (2010). Mobile-izing health workers in rural India. In Proceedings of the SIGCHI Conference on Human Factors in Computing Systems (pp. 1889-1898).

Rao, S. (2010). Digital review of Asia Pacific 2007-2008. Journalism and Mass Communication Quarterly, 87(3/4), 659.

Rizwan, A. (2016a). Meet Bina Khan, product owner at TPS. Dawn. Retrieved from http://www. dawn.com/news/1296703.

Rizwan, A. (2016b). Meet Zainab Hameed, head of IT at Glaxo Smith Kline. Dawn. Retrieved from http://www.dawn.com/news/1296703.

Rizwan, F. (2016c). Meet Zahra Khan, team lead at software house 'Arbisoft'. Dawn. Retrieved from http://www.dawn.com/news/1289702.

Rizwan, F. (2016d). Meet Sara Hassan, team lead and principal software engineer at 'NetSol'. Dawn. Retrieved from http://www.dawn.com/news/1292593.

Siddiqui, A., Shah, F., \& Memon, Z. A. (2010). Accessibility of antenatal services at primary healthcare facilities in Punjab, Pakistan. Methods, 2011.

Tariq, A., Tanwani, A., \& Farooq, M. (2009). User centered design of e-health applications for remote patient management. In 10th Annual Conference of the NZ ACM Special Interest Group on Human-Computer Interaction, CHINZ 2009, Auckland, NZ.

The rise of mobile and social media use in Pakistan. (2015). Avaialable at :https://www.dawn.com/ news/1142701.

Tomlinson, M., Solomon, W., Singh, Y., Doherty, T., Chopra, M., Ijumba, P. ... Jackson, D. (2009). The use of mobile phones as a data collection tool: A report from a household survey in South Africa. BMC Medical Informatics and Decision Making, 9(1), 51. 
Tomlinson, M., Rotheram-Borus, M. J., Swartz, L., \& Tsai, A. C. (2013). Scaling up mHealth: Where is the evidence? PLoS Med, 10(2), e1001382.

UNICEF Pakistan. (2010). UNICEF supports Lady Health Workers in Pakistan. Retrieved from https://www.youtube.com/watch?v=eeJTHlGM7Q0.

van Heerden, A., Tomlinson, M., \& Swartz, L. (2012). Point of care in your pocket: A research agenda for the field of m-health. Bulletin of the World Health Organization, 90(5), 393-394.

Wazir, M. S., Shaikh, B. T., \& Ahmed, A. (2013). National program for family planning and primary health care Pakistan: A SWOT analysis. Reproductive Health, 10(1), 1.

Westbrook, J. I., Braithwaite, J., Georgiou, A., Ampt, A., Creswick, N., Coiera, E., et al. (2007). Multimethod evaluation of information and communication technologies in health in the context of wicked problems and sociotechnical theory. Journal of the American Medical Informatics Association, 14(6), 746-755.

Open Access This chapter is licensed under the terms of the Creative Commons Attribution 4.0 International License (http://creativecommons.org/licenses/by/4.0/), which permits use, sharing, adaptation, distribution and reproduction in any medium or format, as long as you give appropriate credit to the original author(s) and the source, provide a link to the Creative Commons license and indicate if changes were made.

The images or other third party material in this chapter are included in the chapter's Creative Commons license, unless indicated otherwise in a credit line to the material. If material is not included in the chapter's Creative Commons license and your intended use is not permitted by statutory regulation or exceeds the permitted use, you will need to obtain permission directly from the copyright holder. 